\title{
La violencia escolar, los manuales de convivencia y la protección integral del niño, niña y adolescente ${ }^{1}$
}

\author{
Nubia Marrugo Núñez \\ nubia.marrugo16@uac.edu.co \\ Carmen Chinchilla Oñate \\ carmen.chinchilla@uac.edu.co \\ Helena Morales Ortega \\ helena.morales@uac.edu.co \\ Universidad Autónoma del Caribe
}

\section{Resumen}

Uno de las formas de violencia adolescente que preocupa en el momento actual es aquella que se presenta en los espacios educativos, la cual ha aumentado la preocupación de los Estados, educadores y padres y madres de familia. En este contexto, se afirma que tres de cada cinco víctimas de bullying piensan en suicidio. En este artículo se busca no solo identificar la existencia del acoso en las escuelas objeto de estudio, sino saber igualmente si las víctimas habían tenido la oportunidad de dar a conocer su situación, pues se evidencia no solo la existencia sino también el aumento de casos de matoneo y violencia escolar en los colegios de Colombia. Se postula, además que las directivas y docentes deben contribuir a hacer cumplir los manuales de convivencia, como solución mediante el respeto de los principios y garantías constitucionales del debido proceso, y así mismo, hacer cumplir las sanciones y procedimientos que se apliquen.

\section{Palabras clave}

Manual de convivencia; bullyng; estudiantes; violencia; adolescentes;

Recibido 23/03/20-Aceptado 15/05/20

\footnotetext{
${ }^{1}$ Este artículo se deriva del proyecto de investigación titulado "Violencia y victimización en tres escuelas del distrito de Barranquilla: Una mirada desde la normatividad de la protección integral del niño, niña y adolescente" desarrollado dentro del Grupo de Investigación Estudios de Género, Niñez y Criminalidad, de la Universidad Autónoma del Caribe. Participaron como auxiliares de investigación los estudiantes Camilo Andrés Fandiño García y Alexander Reyes Avendaño.
} 


\title{
School violence, coexistence manuals and comprehensive protection for children and adolescents
}

\begin{abstract}
One of the forms of adolescent violence that worries at the present time is that which occurs in educational spaces, which has increased the concern of States, educators, and parents. In this context, it is stated that three out of five victims of bullying think of suicide. This article seeks not only to identify the existence of bullying in the schools under study, but also to know if the victims had had the opportunity to publicize their situation, since it is evident not only the existence but also the increase in cases of bullying and school violence in schools in Colombia. It is also postulated that the directives and teachers must contribute to enforcing the coexistence manuals, as a solution by respecting the constitutional principles and guarantees of due process, and likewise, enforcing the sanctions and procedures that are applied.
\end{abstract}

\section{Keywords}

School violence; curriculum; school; teachers; students. 


\section{Violência escolar, manuais de convivência e proteção abrangente para crianças e adolescentes}

\section{Resumo}

Uma das formas de violência adolescente que preocupa atualmente é a que ocorre nos espaços educacionais, o que aumentou a preocupação de Estados, educadores e pais. Nesse contexto, afirma-se que três em cada cinco vítimas de bullying pensam em suicídio. Este artigo busca não apenas identificar a existência de bullying nas escolas estudadas, mas também saber se as vítimas tiveram a oportunidade de divulgar sua situação, uma vez que é evidente não apenas a existência, mas também o aumento de casos de violência. bullying e violência escolar nas escolas da Colômbia. Postula-se também que as diretrizes e os professores devem contribuir para o cumprimento dos manuais de convivência, como solução, respeitando os princípios constitucionais e as garantias do devido processo legal e, do mesmo modo, aplicando as sanções e procedimentos aplicados.

\section{Palavras chave}

Manual de convivência; bullying; estudantes; violência; adolescentes; 


\section{Introducción}

La violencia: la Organización Mundial de la Salud (2002) ha definido la violencia como "El uso intencional de la fuerza física o el poder contra uno mismo, hacia otra persona, grupo o comunidades y que tiene como consecuencias probables lesiones físicas, daños psicológicos, alteraciones del desarrollo, abandono e incluso la muerte" (párr. 1). Según esta definición, la violencia puede expresarse en diferentes contextos y pueden también ser diversos los participantes en ella: individuos, poblaciones, organizaciones o instituciones, indicando además esta definición los diferentes efectos de la misma.

\section{Almenares et al la define como}

[...] cualquier relación, proceso o condición por la cual un individuo o grupo social viola la integridad física, psicológica o social de otra persona. Es considerada como el ejercicio de una fuerza indebida de un sujeto sobre otro, siempre que sea experimentada como negativa (1999, p. 285).

La violencia es un fenómeno multicausal y puede asumir diferentes formas; ello es necesario tenerlo en cuenta para una eficaz intervención tendiente principalmente a su prevención. Algunas formas de la violencia son muy visibles como las guerras entre Estados, las guerras internas entre grupos, o entre etnias diferentes dentro de un mismo Estado. Otras formas de violencia son poco visibles, desconocidas o ignoradas durante mucho tiempo; tal es el caso del maltrato y abuso sexual infantil, la violencia doméstica en la cual las mujeres -las más victimizadas- permanecieron, golpeadas, heridas ultrajadas o humilladas por sus parejas sin atreverse a denunciar y ni siquiera a hablarlo con sus familiares. Puede tratarse igualmente del maltrato al adulto mayor por parte de sus familiares o de sus cuidadores. Es decir, distintas formas de violencia que se producen al interior de la familia, un espacio llamado a proteger y brindar las condiciones necesarias para un desarrollo integral y armonioso al individuo.

En la presentación del informe "Yo a eso no juego", realizado por Calmaestra et al (2016) para la ONG Save the Children, se puede leer: 
Cada año millones de niños y niñas en todo el mundo se convierten en víctimas de una violencia silenciada. En cualquier país, cultura y estrato social, los niños y niñas se enfrentan a distintas formas de abuso, de abandono y de explotación. Esta violencia adopta muchas formas y se adapta a muchos contextos. Ocurre en sus casas, escuelas, en las instituciones, en sus comunidades o en medio de una emergencia. La violencia contra la infancia, que puede adoptar múltiples y cambiantes formas, nunca es justificable, independientemente de la gravedad de las lesiones producidas, de las consecuencias sobre el desarrollo de los niños y niñas, de la persistencia, la duración o la aceptación social de una forma concreta de violencia (Calmaestra, et al 2016, p. 8).

En lo relacionado con la violencia a niños, niñas y adolescente, se asiste hoy a una alarmista evolución del problema, particularmente la violencia adolescente. Un estudio realizado en Canadá (Le Blanc, 1999) anota que no es tanto el número de adolescentes violentos el que progresa sino la frecuencia de sus actos. Uno de las formas de violencia adolescente que preocupa en el momento actual es aquella que se presenta en los espacios educativos.

\section{La violencia escolar}

A través de la historia, la escuela ha jugado un rol importante en el proceso de formación del individuo. Sin lugar a dudas es uno de los agentes principales en la socialización del ser humano. No se puede negar la enorme importancia que tiene esta institución en el sistema de producción y reproducción social, en la formación del comportamiento cultural, pues a través de ella se trasmiten valores, normas, reglas, símbolos, conocimientos y técnicas.

Al decir de Echavarría Grajales (2003, p.2) existe

[...] la necesidad de hacer visible la escuela, no ya como aquella institución educativa ejecutora de procesos administrativos y técnicos, que ya bien importantes son, sino, y además, como una lectora que, desde su dimensión pedagógica e independientemente de que lo tenga claro o no, se ocupa por la socialización y la construcción de sentidos de identidad tendientes a la configuración de sujetos morales que se hacen como tales en la interacción y la confrontación continua con sus pares, sus maestros y otros agentes de socialización, alrededor de temáticas conflictivas consideradas como problemas morales, construcción de normativas y valores propios de la convivencia, argumentación y contra-argumentación frente a las sanciones normativas, asunción responsable y comprometida en la toma de decisiones y sus consecuencias, visualización en las 
actitudes de una perspectiva del derecho basada en el respeto y de una perspectiva del deber basada en la responsabilidad.

La escuela constituye, pues, un importante agente social y es el lugar donde se supone reciben formación, educación y aprenden a ser solidarios los jóvenes; allí ellos pasan mucho tiempo y se establecen relaciones que pueden ser de amistad y compañerismo entre los estudiantes o pueden expresar relaciones negativas entre ellos. Efectivamente, una constatación ha sido hecha: el espacio escolar también puede constituir un entorno donde el joven se ve expuesto a la violencia, de manera que la escuela puede convertirse en el lugar donde él o ella, además de prepararse mediante la formación y el desarrollo de competencias para la vida social y profesional futura, se ve confrontado como víctima de la violencia o puede ser un testigo que aprenderá a cometer actos violentos en ese espacio que se supone está concebido para formarlo en la sana convivencia social.

El aumento de los casos de violencia entre iguales en los centros educativos ha incrementado la preocupación de los Estados, educadores, padres y madres de familia. Hay que señalar, sin embargo, que la agresión en el ámbito educativo puede darse entre los diversos actores: entre pares, entre estudiantes y profesores o viceversa, entre los padres de familia y los profesores, o entre los directivos y los docentes, y entre los directivos y los estudiantes, razón por la cual es preferible hablar de las violencias en el espacio escolar.

Sobre ello, afirma Martínez Rojas

Cuando se habla de violencia en la escuela casi siempre se hace referencia a las agresiones y actos violentos que se suscitan entre los estudiantes y sus compañeros, y si bien es uno de los problemas más serios de la convivencia, también hay otro tipo de violencia o agresión que se da entre la institución o sus profesores, y los estudiantes. Este es un tipo de violencia del cual casi no se hacen estudios o indagaciones, porque parece estar legitimado o normalizado por el sistema mismo. Se podría hablar entonces de un tipo de violencia institucionalizada (2014, p.29).

En un estudio realizado por la Organización de las Naciones Unidas (2006) observan lo siguiente:

La violencia perpetrada por profesores u otros trabajadores de la escuela, con o sin la explícita o tácita aprobación de los ministros de educación y otras autoridades que supervisan las escuelas, puede revestir la forma de castigos corporales, diversos castigos psicológicos crueles y humillantes, violencia sexual o motivada por el género y acoso 
entre compañeros. Los castigos corporales tales como las palizas y los golpes con vara son práctica habitual en las escuelas de numerosos países. La Convención sobre los Derechos del Niño exige a los Estados partes que tomen las medidas apropiadas para garantizar que en las escuelas la disciplina se administre de modo acorde con la Convención. La Iniciativa Global para Acabar con todo Castigo Corporal hacia Niños y Niñas señala que 102 países han prohibido el castigo corporal en la escuela, pero el cumplimiento de esa norma es desigual (p. 16).

En diversos países se han realizado investigaciones sobre las violencias en la escuela tanto la que se da entre los estudiantes, así como la que se presenta entre otros actores de la comunidad educativa. En España, por ejemplo, se realizó un estudio sobre la violencia contra profesores en la enseñanza pública de la comunidad de Madrid (Piñuel, 2006), a través de la cual se indagó sobre los riesgos psicosociales que afectan a profesores por los efectos de la violencia que sufren. Se encuestaron más de 6.000 profesores de 237 centros de enseñanza pública y se midieron 235 variables que afectan su trabajo como docentes. Los resultados del estudio muestran que el $92 \%$ de los profesores dijeron que la violencia se ha incrementado en los últimos años. Los datos revelaron también que el $24 \%$ de los docentes ha sido víctima de actos violentos en sus centros educativos; que el $75 \%$ de esos actos violentos son realizados por los estudiantes, mientras que el $36 \%$ son realizados por los padres de éstos. El $74 \%$ de los profesores también señaló que el incremento de la violencia en los centros educativos se debía, entre otras causas, al abandono de la tarea educativa por parte de los padres, lo cual presenta un problema para los docentes pues además de la tarea de enseñar le toca asumir el rol paternal que la madre y /o el padre no están cumpliendo, llamados por ello "padres dimisionarios", que dejan la educación de sus hijos en manos de los profesores exclusivamente. Ante ello, "Los hijos son jóvenes que portan una llave para abrir la casa que normalmente está vacía cuando llegan de la escuela", afirmaron los profesores (Piñuel, 2006, p. 17).

Otra causa señalada por los docentes, es la violencia en la sociedad (66\%); la crisis de valores fue indicada por el $65 \%$ como una causa de la violencia en las escuelas; el $58 \%$ lo atribuyó a la proliferación de modelos sociales violentos en los medios; la violencia en el seno de la familia para el 35\% es una de las causas de la violencia escolar; el 30\% señaló la falta de integración social de los alumnos, entre otros. 
Así mismo, se puede revelar la investigación realizada por Gómez Nashiki (2014) en Colima - México—, que buscó analizar la experiencia de docentes de educación secundaria que han sufrido algún tipo de violencia por parte de sus alumnos a lo largo de su trayectoria. Utilizando la técnica de la entrevistas en profundidad, se realizaron 25 entrevistas en diferentes municipios de Colima, indagándose la forma como los docentes, tanto de escuelas públicas como privadas, experimentaron la violencia física y verbal en su contra; así también se preguntó sobre las distintas actitudes y acciones tales como: el acoso, el desafío a la autoridad, las agresiones personales o a sus bienes y cuestionamientos al momento de aplicar la disciplina y las normas que marca la institución. Como resultado,

[...] los docentes señalan que las agresiones han aumentado considerablemente en los últimos años; la violencia más frecuente es de tipo verbal - aunque también se han mencionado casos de violencia física - y cada vez se presentan más actos delictivos en su contra. Las situaciones que identifican son un malestar cotidiano en su trabajo, problemas para ejercer su práctica y mantener el control en el aula, dificultades para comprender las actitudes de los adolescentes, no saber cómo manejar los conflictos y carecer de estrategias, así como de recursos pedagógicos y de apoyo institucional para poder afrontar esta situación (Gómez, 2014, p.19)

Otro estudio realizado en Latinoamérica, sobre las relaciones interpersonales en la escuela, señala que "el desinterés, la disciplina y las violencias de parte del alumnado, junto a la permanente desautorización familiar y social, hacen que en los buenos educadores se observe un evidente deterioro personal y profesional" (Castro, 2006, p.10). En ese estudio, los docentes fueron encuestados por el Instituto Internacional de Planeamiento de la Educación (IIPE-Uniesco, 2005), y los resultados muestran que

el 47,5\% de los 2384 docentes argentinos consultados prefiere dejar su puesto actual al frente de los alumnos y no enseñar en la clase. Igual pasa para el 68\% de los docentes peruanos, el $40 \%$ de los brasileños y del $36 \%$ de los uruguayos que participaron de la encuesta, cuyo alcance comprendió a casi 13.000 maestros y profesores de la región. (Castro, 2006, p.10).

En Colombia, algunos investigadores (Parra, et al [1992]; Valencia, [2004]) se han preocupado por el problema de las violencias en el espacio escolar, analizando la importancia 
de la formación ciudadana de los estudiantes, el papel de la escuela en la formación de individuos para la participación activa, pacífica, democrática y justa en la sociedad civil. Ellos señalan también cómo la escuela, además de transmitir, distribuir y crear conocimiento, debe proporcionar una formación en valores para la convivencia en la sociedad, objetivos estos a los cuales debe apuntar la calidad de la educación.

\section{El bullyng: una forma de violencia en la escuela}

Una de las ideas más comunes que surgen en la mente de la mayoría de las personas, cuando se habla de la violencia en la escuela, es el problema de la intimidación entre estudiantes, como una subcategoría de la conducta violenta en las instituciones educativas. La intimidación, conocida también como acoso escolar, es una de las tácticas adoptadas por los jóvenes que se consideran más fuertes contra aquellos compañeros vistos como débiles. Validos de su "superioridad" estos jóvenes agresores son capaces de crear un sentimiento de temor en la mente del acosado, de tal manera que les permite ejercer su poderío sobre el otro y hacerlo hacer cualquier cosa que ellos quieran o hacer con ellos lo que quieran. Investigaciones realizadas en distintos países (Martínez Rojas [2014]; Castro, [2006]), muestran a jóvenes maltratados, intimidados, acosados por otros en la escuela, observándose entonces que la violencia escolar entre iguales es otra de esas violencias cotidianas, invisibles en algunos partes más que en otras, un hecho importante que violenta los derechos humanos de quien la soporta como víctima de ella.

La agresión que se da entre los pares en la escuela, llamado también bullying o intimidación escolar, consiste en

[...] una forma de agresión repetida y sostenida en el tiempo que ejerce un estudiante (el agresor) sobre otro (la víctima) ante la mirada de sus compañeros (los espectadores), con el fin de someterlo y ejercer poder sobre él, impidiendo que la víctima genere estrategias o acciones que le permitan liberarse de dicho sometimiento. Ese tipo de agresión puede ir desde el daño físico hasta el psicológico (Martínez, 2014. p.28).

En Colombia la Honorable Corte Constitucional, en la sentencia T- 478 de 2015 señala:

[...] una definición amplia, y respaldada por la literatura científica sobre la materia, 
indica que este fenómeno (conocido también como acoso escolar o bullying) es la agresión repetida y sistemática que ejercen una o varias personas contra alguien que usualmente está en una posición de poder inferior a la de sus agresores. Esta deliberada acción sitúa a la víctima en una posición en la que difícilmente puede escapar de la agresión por sus propios medios.

En virtud de que la experiencia de la intimidación no es un mal necesario en la vida de un niño o un adolescente, en nuestro estudio se les preguntó a los estudiantes: ¿habían sido víctimas de bullying, de acoso o matoneo alguna vez y con quién lo habían hablado? (Gráfica $1)$.

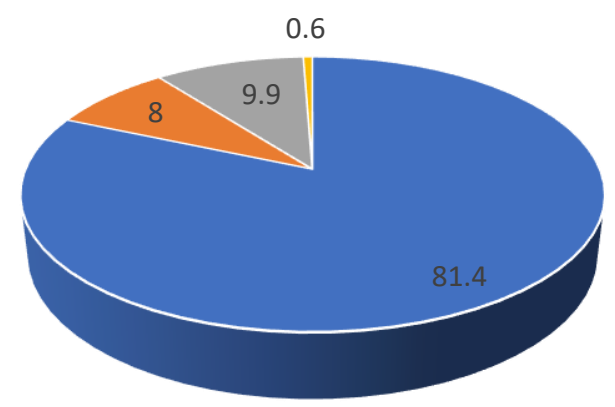

- NO HA SIDO VICTIMA DE BULLYING

- HA SIDO VICTIMA DE BULLYING, PERO NO LO HA HABLADO CON NADIE

- VICTIMA DE BULLYING Y LO HE HABLADO CON MIS PADRES

Gráfica $1^{\circ}$. ¿Ha sido víctima de bullying, de acoso o matoneo alguna vez? ¿Con quiénes has hablado? Fuente: autoría propia.

El 81,4 \% manifestó no haber sido víctima de bullying, el 9,9 \% dijo haber sido víctima, pero no lo había hablado con nadie. El 0,6\% dijo haber sido víctima de bullying y haber hablado del tema con sus padres y el $8 \%$ también dijo haber sido víctima de acoso escolar y haberlo hablado con el rector o director de grupo de la escuela o colegio. (Gráfica 1)

Se quiso no solo identificar la existencia del acoso en las escuelas objeto de estudio, sino saber igualmente si las víctimas habían tenido la oportunidad de dar a conocer su situación, ya que los diferentes estudios realizados al respecto han puesto de presente que, por lo general, este comportamiento no desaparece por sí mismo y, al contrario, empeora con el tiempo y requiere, por lo tanto, de la intervención de los adultos, principalmente. Tanto maestros como autoridades escolares y padres de familia deben tratar directamente la problemática. 
Ante ello, se les realizó por lo tanto, la siguiente pregunta: En caso de que te hayas quejado con las directivas de la escuela por ser víctima de bullying, ¿cómo ha sido la reacción de éstas? (Gráfica $2^{\circ}$ )

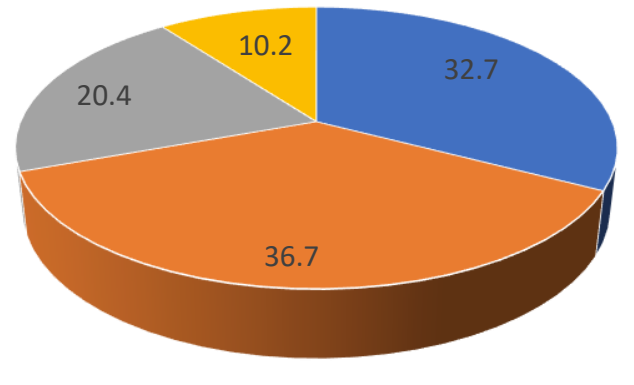

- NUNCA CONVERSÓ

- MÁS BIEN REGULAR
- MUY BUENA, LA SITUACIÓN SE TERMINÓ

- INDIFERENTE O MALA

Gráfica $2^{\circ}$. ¿Se ha quejado con las directivas de la escuela por ser víctima de bullying? ¿Cuál ha sido la reacción de éstas? Fuente: autoría propia.

Los resultados muestran que el $32,7 \%$ de las víctimas nunca conversó sobre el tema con las directivas de la escuela, pero para el 36,7 \% la reacción fue muy buena, pues "la situación se terminó, no volví a ser molestado" dijo un encuestado. El 20,4\% de las víctimas de bullyng calificó la reacción de más bien regular ("la situación se calmó un poco, pero aún me molestan"). Para el 10,2 \% de las víctimas la reacción fue Indiferente o mala ("no hicieron nada”). Nótese que para el 36,7 \% de las víctimas la reacción fue muy buena, señalando que no volvieron a ser molestados en tal situación y, aunque, el porcentaje es menor con relación a aquellos que califican la reacción de las directivas como de indiferente, es preocupante, pues los intimidados en muchas ocasiones viven en un clima de miedo, de temor, de impotencia, pues no se puede aceptar que haya en la escuela un solo estudiante viviendo tal situación. La consigna de maestros y directivas en las escuelas debe ser "cero tolerancia al bullyng"; "no al mal trato". Las escuelas deberán implementar programas efectivos para la promoción de la sana convivencia, la construcción de ambientes escolares favorables para el 
desarrollo integral de los niños y niñas y adolescentes y el buen entendimiento entre los estamentos de la institución.

También se les preguntó: En caso de que te hayas quejado con tus padres por considerarte víctima de bullying, ¿cómo consideras que ha sido la reacción de ellos?
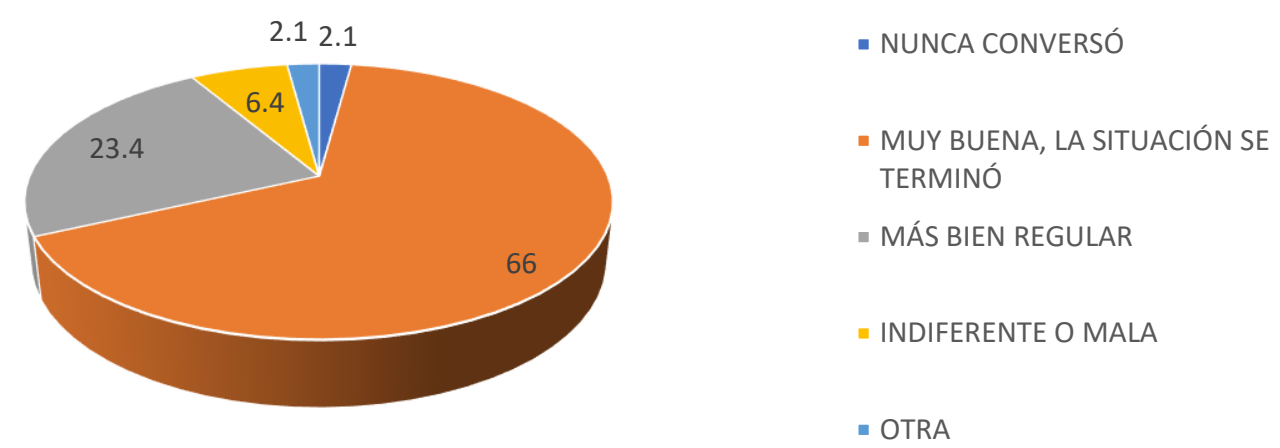

\section{Gráfica $3^{\circ}$. ¿Se ha quejado con sus padres por considerarse víctima de bullying?} La reacción de ellos. Fuente: autoría propia.

El 2,1\% de los encuestados que se consideró víctimas de bullyng dijo que nunca conversó de la situación con sus padres. El 66 \% expresó que la reacción fue muy buena: "Mis padres fueron a la escuela, hablaron y la situación se terminó, no volví a ser molestado”, manifestó un entrevistado. El 23,4 \% considera la reacción como más bien regular: "Mis padres me escucharon y me dieron unas recomendaciones para defenderme”. Para el 6,4 \% la reacción de sus padres fue Indiferente o mala: "no hicieron nada”, indicó uno de los encuestados. $\left(\right.$ Gráfica $\left.3^{\circ}\right)$.

A la pregunta: ¿Has presenciado cómo otro u otros estudiantes acosan o matonean a un compañero o compañera de tu clase o de la escuela? (Gráfica $4^{\circ}$ ). Los 516 estudiantes que hemos encuestado respondieron así: el 59,7\% manifestó que nunca ha presenciado acoso o matoneo a un compañero o compañera de su clase o de la escuela, mientras que un alto porcentaje, es decir el 40,4 \%, dijo haber presenciado estos actos entre el año 2012 al 2014 (periodo de observación del estudio), lo cual debe llamar la atención de las escuelas objeto de estudio en sus estrategias para prevenir el maltrato entre los estudiantes. 


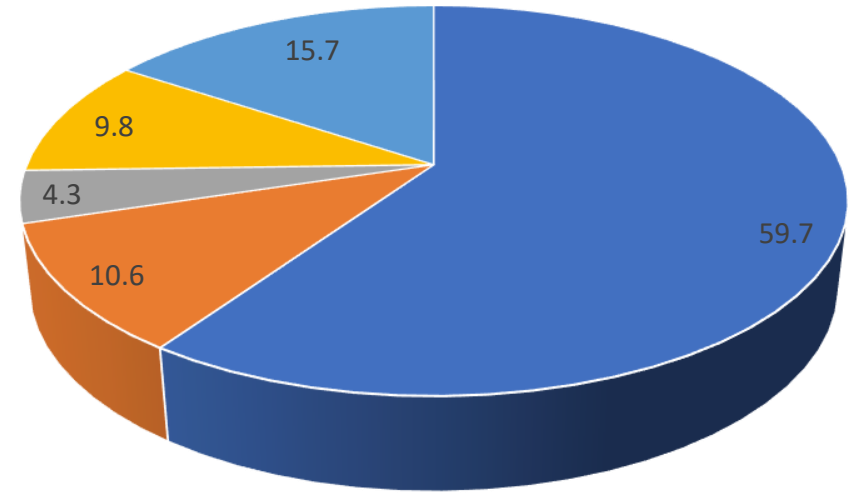

- NUNCA HA PRESENCIADO

- ANTES DE 2012

- EN 2012

EN 2013

- EN 2014

Gráfica $4^{\circ}$. ¿Ha presenciado cuando otro u otros estudiantes acosan o matonean a un compañero o compañera? Fuente: autoría propia.

El problema de la violencia en la escuela es, pues, tema recurrente, que preocupa, como se puede notar, desde hace ya algunos años. Las formas que asume esta violencia son muy diversas, ella va desde agresiones verbales, hasta verdaderos atentados a la integridad física y psicológica en algunos casos con consecuencias fatales.

Se dice que tres de cada cinco víctimas de bullying piensan en suicidio, según quedó establecido en un estudio realizado por Agenda Pandi-Friends United Foundation (2015). Mediante una encuesta realizada en las principales ciudades del país, se obtuvieron cifras que evidencian no solo la existencia sino también el aumento de casos de matoneo y violencia escolar en los colegios de Colombia. Unos 5.500 niños, niñas y adolescentes escolarizados, entre 12 y 18 años, resultaron ser víctimas: el $35 \%$ de maltratos físicos y un $65 \%$ de maltratos psicológicos. Entre los indicadores de este estudio se evidenció que una de las causas más comunes de bullying se relaciona con la homofobia, con un 30\%, seguida de la discriminación por razón de raza (25\%), por ser hincha o barrista del equipo contrario (20\%), rechazo o matoneo por alguna discapacidad con un $10 \%$ y el matoneo por aspecto físico con un $10 \%$. El bullying, por alguna otra condición diferente a las nombradas, ocupó un 5\% en la encuesta. 
Los abusadores, según este estudio, utilizan varios métodos de violencia escolar, entre los que se encuentran los delitos informáticos, las agresiones físicas, la inducción al suicidio o a realizar actos delictivos como el hurto, es decir, el estudio reveló que una de las modalidades de matoneo que se está llevando a cabo en varios colegios de Colombia es la presión que realizan estudiantes sobre otros para obligarlos a que se vinculen a organizaciones delictivas. Y unos de los casos que más llamaron la atención y encendieron las alarmas lo constituyen los delitos sexuales, que agrupan intentos de violación, el uso de fotografías para material pornográfico, entre otros. Estos casos, según la investigación, serían unos de los más frecuentes, pero que, a pesar de ello, no son denunciados por vergüenza de la víctima.

Ante este tipo de acciones, se encontró en el estudio señalado, que, de los adolescentes consultados, víctimas de matoneo, 3 de cada 5 manifestaron haber pensado en el suicidio y uno de cada 3 lo intentan. La investigación mostró también que en los colegios de estratos altos se recurre más al hostigamiento y calumnia por redes sociales, estando en primer lugar Facebook, seguido de Twitter y Youtube y WhatsApp.

El citado estudio de la Organización de Naciones Unidas (2006, p.17) afirma:

[...] en los centros educativos también tiene lugar la violencia sexual y la violencia por motivos de género. En gran parte esta violencia la ejercen los profesores y estudiantes varones contra las muchachas. En muchos Estados y regiones la violencia ataca también cada vez en mayor medida a las personas jóvenes homosexuales, bisexuales y transgenéricas. El hecho de que los gobiernos no promulguen y apliquen leyes que protejan de forma explícita a los estudiantes de la discriminación favorece la violencia sexual y de género.

En este mismo sentido, la investigación realizada por el profesor Enrique Chaux, (2008) con la participación de 87.302 estudiantes, de grado quinto a undécimo, de colegios privados y públicos, ha mostrado que se trata de un fenómeno que afecta de forma grave a la víctima, la cual puede experimentar una fuerte depresión con riesgo de suicidio. Para el caso de los agresores, se señala que están en alto riesgo de vincularse a pandillas y grupos delincuenciales. Igualmente los testigos o espectadores de los hechos se ven afectados por estos. 
En nuestro estudio con la pregunta: ¿Cuál ha sido tu reacción o qué has hecho cuando has presenciado el acoso, la agresión o matoneo a tu compañero o compañera? (Gráfica $5^{\circ}$ ), se buscó evidenciar cuál era la actitud de los espectadores, los resultados son los siguientes:
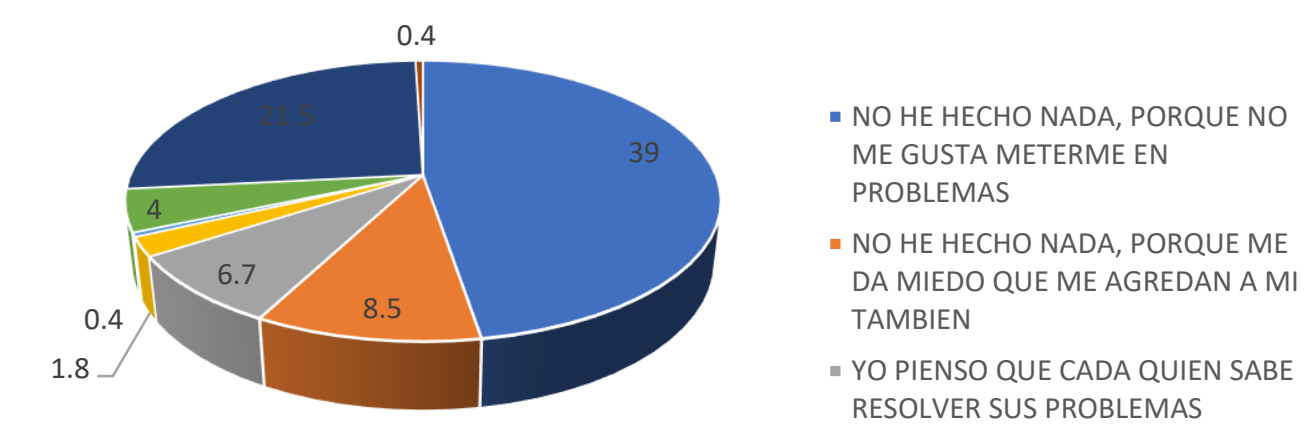

Gráfica $5^{\circ}$. ¿Reacción a qué ha hecho cuando ha presenciado el acoso, la agresión o matoneo de un compañero o compañera? Fuente: autoría propia.

El 39\% indicó: "No he hecho nada, porque no me gusta meterme en problemas ", es decir son los llamados espectadores ajenos, aquellos que se muestran como neutrales y no quieren implicarse, sin ser conscientes que al callar están tolerando el bullying. A este porcentaje le sigue el de aquellos (8,5\%) que dijeron: "No he hecho nada, porque me da miedo que me agredan a mí también". Estos son individuos que, igualmente, sienten temor de ser víctimas, y también pueden llegar a sentir sentimientos de culpa, de impotencia, por no atreverse a defender a la víctima o verse obligados a no actuar. Un 6,7\% respondió: "Yo pienso que cada quién debe resolver sus problemas". Aquí se está frente a una situación de indiferencia, en la que él o la testigo siente que el problema no le concierne, le es ajeno. El 1,8\% expresó: "Yo pienso que esa persona se busca y se merece lo que le pasa". En este caso se culpabiliza a la víctima de su situación. Se encontró también en menor porcentaje, un $0.4 \%$, el grupo de los reforzadores, que son aquellos que, aunque no acosan de manera directa, observan las agresiones, las aprueban e incitan y pueden llegar a ser también compinches del agresor. Ellos respondieron: "La verdad es que me gusta ver cómo los otros acosan a esa persona".

Por otro lado, un 4\% dijo: "La verdad no hago nada porque los profesores, ni las directivas tampoco muestran interés", de ahí la importancia de la preparación y sensibilización de los docentes frente a este problema. 
Finalmente, el 21,5\% manifestó su deseo de “hacer algo para parar esa situación”, pero manifiesta no saber cómo, lo cual confirma la necesidad de lanzar en las escuelas campañas en contra del matoneo escolar, realizar acciones preventivas que impliquen la capacitación para los estudiantes, los padres, docentes, autoridades y mecanismos de defensa para las víctimas, actividades estas que, en los colegios, realicen la confrontación con las víctimas, los victimarios y los docentes. Finalmente, el 0,4\% manifestó que cuando observa tal situación, "se mete a defender a la víctima"
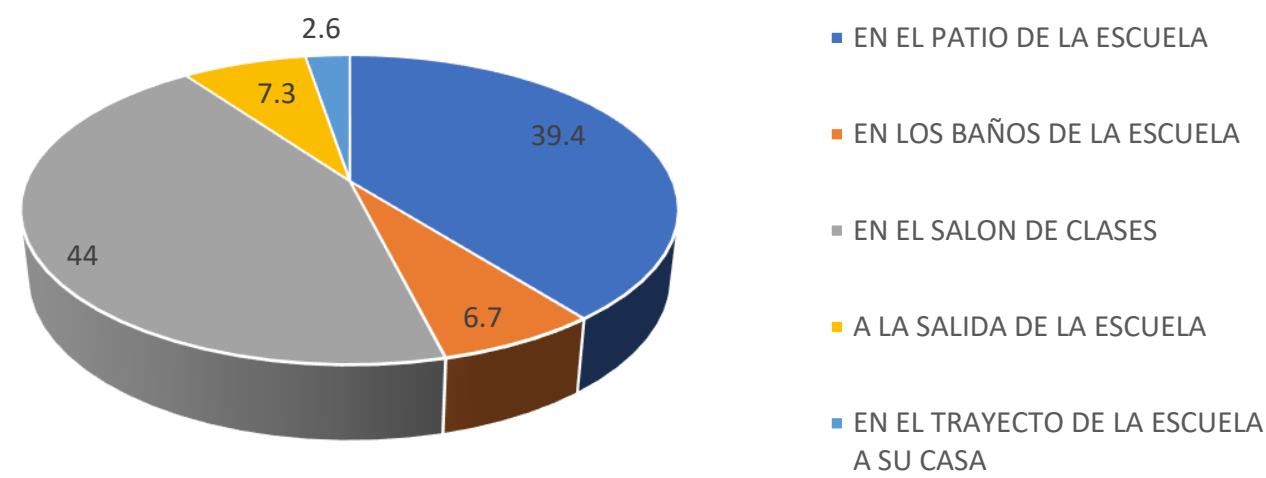

\section{Gráfica $6^{0}$. Lugares donde ha presenciado el acoso al compañero o compañera}

Fuente: autoría propia

En cuanto al lugar donde los estudiantes han presenciado estos actos, en nuestra investigación los resultados muestran que el 39,4\% señala el patio de la escuela, el 6,7\% señaló los baños de la escuela como el lugar donde había presenciado el acoso, el $44 \%$ el salón de clase, el 7,3\% a la salida de la escuela, y el 2,6 \% en el trayecto de la escuela a su casa $\left(\right.$ Gráfica $\left.6^{\circ}\right)$.

Los espacios físicos han sido señalados como elementos importantes dentro de las condiciones necesarias para el proceso eficaz del aprendizaje escolar, con influencia también en la convivencia. Es importante conocer los lugares en donde se dan las manifestaciones de maltrato para poder implementar programas de prevención. Nótese que un alto porcentaje de nuestro estudio señala el patio de la escuela, pues se sabe que los recreos que se desarrollan generalmente en este sitio son los espacios propicios para que los estudiantes interactúen de una manera más libre, ya que allí pueden aunar lazos de amistad y camaradería, pero también estos lugares han sido señalados como espacios donde más pueden ser víctimas de malos 
tratos por parte de sus compañeros. Así, el estudio de Pereira et al (2002), señala que el patio de recreo es uno de los lugares de la escuela donde se produce el porcentaje más elevado de comportamientos agresivos y malos tratos entre compañeros (bullying). Allí "el 76\% de los niños víctimas de malos tratos por parte de sus compañeros en la escuela primaria son victimizados en los recreos" (Pereira, et al, 2002, p.300). Para prevenir esos comportamientos, una mejor vigilancia en el recreo, así como la realización de actividades lúdicas programadas por la institución, pueden ayudar y hacer que la víctima se sienta más segura.

En cuanto a la edad en la cual puede manifestarse estos comportamientos, según Chaux, (2008), desde el preescolar se presentan casos de acoso escolar o matoneo, constatándose en este grado que los agresores suelen intimidar a muchos. Esta situación no se presenta solo en Colombia, pues en espacios culturales diferentes también se ha evidenciado. Efectivamente, en un estudio realizado por Unicef en Francia, con participación de los equipos de investigación de siete universidades de ese país, lo que surgió del estudio hizo plantear a los investigadores que "era agradable y preocupante" al mismo tiempo, señalando que aunque a la gran mayoría de los niños les gusta la escuela y se sienten bien al respecto, una parte minoritaria pero importante declaró ser víctima de violencia recurrente y hostigamiento físico y verbal. Para más del 10\% de los niños encuestados, la escuela es un lugar de sufrimiento. Señalo Unicef-Francia la gravedad de las consecuencias psicosociales de la violencia en individuos tan jóvenes, con personalidad en construcción, tan frágiles (Unicef- Francia 2011). Chaux (2008) afirma que, empezando la secundaria, la intimidación tiende a concentrarse en unos pocos, en los más vulnerables, los que tienen menos amigos. Igualmente,según este autor, en aquellos colegios donde hay mayores diferencias socioeconómicas, se presentan más casos de acoso escolar. Los de estrato más alto tienden a ser más agresores. Se ha establecido igualmente que en los colegios privados se presenta más la intimidación a través de internet, es el llamado cyberbullyng, siendo los agresores los estudiantes de más edad y pertenecientes a altos estratos económicos, mientras que en los colegios públicos es más explícita, "con golpes e insultos".

En cuanto al desempeño académico, asegura Chaux, los colegios con más intimidación tienen los resultados más bajos, lo que es un indicio para que las autoridades distritales del sector educativo comiencen por allí a trabajar de manera más constante y específica. 
En la ciudad de Barranquilla, la investigación realizada por Hoyos (2005) muestra que el problema del acoso existe, que se expresa principalmente por el maltrato verbal, siendo el principal el apodo, seguido por el chisme y los insultos. También hay agresiones físicas y de exclusión. En nuestro estudio, las víctimas del acoso manifestaron igualmente que el maltrato es más de tipo psicológico, verbal y, en menor medida, de tipo físico como empujones.

\section{Los manuales de convivencia y la violencia escolar}

La palabra convivencia se refiere a la acción de convivir, es decir, vivir en compañía con otra u otras personas, lo cual puede implicar el cohabitar, pero también el compartir de manera constante con otra persona diferente a uno mismo diariamente, de allí que se hable de convivencia familiar, convivencia laboral y convivencia escolar, entre otras. En el proceso de la convivencia se establecen relaciones que deben tener un carácter armonioso, pacífico, tolerante, con arreglo conciliatorio de los conflictos que se puedan presentar en esa interacción, pues las relaciones humanas no están exentas de conflictos. Cuando esos conflictos no se arreglan de manera pacífica, se presenta, entonces, la mala convivencia.

La convivencia es posible dado el carácter sociable del ser humano, quien es un ser gregario, que no puede vivir solo fácilmente. La interacción con otras personas ha ido fundamental para el desarrollo de la humanidad, por lo tanto, convivir con otros ha sido una necesidad histórica para la humanidad misma. Pero no basta convivir, sino que es necesario convivir en armonía, por lo cual una sana convivencia requiere, además de la tolerancia, el respeto a las normas de convivencia que el grupo social ha aceptado en su mayoría. Sobre ello, indica Bembibre (2013):

El reconocernos como seres sociales es un elemento central para conocernos mejor y luchar día a día por lograr establecer una convivencia armoniosa y pacífica. Aunque esto es complicado, las sociedades han siempre buscado establecer normas y leyes que permitan evitar o prevenir conflictos así como también sancionarlos en el caso de que existan. La convivencia entonces ha necesitado estar enmarcada por distintos soportes legales y de valores sociales que nos educaran en la tolerancia o el respeto hacia el otro. De todos modos, nunca estos valores se aplican en su totalidad ya que las sociedades humanas son de por sí conflictivas (p.1). 
En los espacios educativos, la convivencia se presenta como un elemento importante, fundamental para lograr los objetivos de los procesos formativos buscados por la institución educativa. Señala Martínez Rojas que la gestión de la convivencia busca

[...] la formación ética y moral de los estudiantes, supuesto de todo el proceso de formación en la convivencia y que debe ser su intencionalidad para que todo aquello que se haga en la institución educativa, bajo la perspectiva de la norma, su asunción y cumplimiento, por parte de los estudiantes, vaya más allá del mero cumplimiento por el cumplimiento, y encuentre un sustento real y efectivo en estos procesos, que buscan un adecuado desarrollo moral, así como una maduración de la conciencia moral y de la capacidad de tomar decisiones responsables y libres, racionalmente sustentadas $(2014$, p. 37).

En el artículo “¿Qué es la convivencia escolar?”, en el sitio web de Colombia aprende, Cortés (2016) plantea:

La convivencia escolar se puede entender como la acción de vivir en compañía de otras personas en el contexto escolar y de manera pacífica y armónica. Se refiere al conjunto de relaciones que ocurren entre las personas que hacen parte de la comunidad educativa, el cual debe enfocarse en el logro de los objetivos educativos y su desarrollo integral.Un ambiente escolar positivo crea relaciones de convivencia pacífica, aporta a la permanencia de los niños, niñas y adolescentes en la escuela, mejora los desempeños académicos y previene situaciones como los embarazos tempranos no deseados, la vinculación laboral temprana, y otras situaciones que limitan su desarrollo integral y ejercicio pleno de sus derechos (Cortés, 2016).

En Colombia, en respuesta al mandato de la Corte Constitucional, en el año 2013 es expedida la Ley 1620 o Ley de Convivencia Escolar, mediante la cual se establece el Sistema Nacional de Convivencia Escolar y formación para el ejercicio de los Derechos Humanos, la Educación para la Sexualidad y la Prevención y Mitigación de la Violencia Escolar. La ley se fundamente en la sentencia de la Corte C T-905 de 2011, frente a los hechos y situaciones problemáticas en las escuelas del país, que instó al Ministerio de Educación para que, en coordinación con el ICBF, la Defensoría del Pueblo y la Procuraduría General, liderara la política para la prevención, detección y atención de prácticas de hostigamiento, acoso o "matoneo escolar". Subsiguientemente, el ordenamiento fue reglamentado por el Decreto 1965 de septiembre 11 del mismo año. Con esta ley se ha buscado dotar a las autoridades públicas, a las instituciones educativas, directivos y docentes, de herramientas necesarias para enfrentar, entre otros problemas, los actos de acoso y violencia escolar. Sin embargo, se 
ha señalado una corresponsabilidad en esta tarea de tal manera que la misma incumbe en igual medida a las familias de los estudiantes y a éstos, pues solamente a partir del trabajo conjunto entre los discentes y familiares, es posible lograr una intervención efectiva en las causas de las violaciones de derechos fundamentales que tienen lugar al interior de los establecimientos educativos.

\section{Los manuales de convivencia}

La Ley 115 de 1994 o Ley General de Educación, estableció la necesidad en los colegios e instituciones educativas del Manual de Convivencia, el cual contiene las reglas a las cuales se sujetarán las relaciones entre los miembros de la comunidad educativa. Este reglamento contiene igualmente los derechos y obligaciones de estudiantes, padres de familia, acudientes, docentes y directivas de la institución. Igualmente, el decreto 1860 de agosto 3 de 1994 por el cual se reglamenta parcialmente la citada ley, en los aspectos pedagógicos y organizativos generales, en su artículo $17^{\circ}$ dispone lo siguiente: "De acuerdo con lo dispuesto en los artículos 73 y 87 de la Ley 115 de 1994, todos los establecimientos educativos deben tener como parte integrante del proyecto educativo institucional, un reglamento o manual de convivencia”. Así mismo, el artículo 87 de la ley 115 de 1994 establece que:

Los establecimientos educativos tendrán un reglamento o manual de convivencia, en el cual se definan los derechos y obligaciones, de los estudiantes. Los padres o tutores y los educandos al firmar la matrícula correspondiente en representación de sus hijos, estarán aceptando el mismo.

Lo anterior implica para los centros educativos el deber de dar a conocer a los padres, tutores o acudientes y a los estudiantes, el manual de convivencia al momento de firmar la matricula. Es indispensable anotar que, en la práctica, esta directriz casi nunca se hace y el manual de convivencia termina siendo impuesto + de manera unilateral por parte de la institución educativa, tanto a los padres como a los educandos, aunque existe la presunción legal de su conocimiento o aceptación, por el hecho de firmar la matrícula.

Sobre ello, ha dicho la Corte Constitucional: 
Por otra parte, para que esos documentos sean oponibles y exigibles a padres de familia y estudiantes, es necesario que, siendo fruto de consenso previo entre los distintos ejes de la comunidad educativa, su contenido haya sido conocido por éstos y aceptado expresamente en el momento de la matrícula. De no ser así, sería una imposición unilateral que no consultaría los intereses, preocupaciones y visión de los llamados a cumplir la normativa establecida en el Manual, lo cual resultaría incompatible con las disposiciones de la Carta (Corte Constitucional, Sentencia T-688 de 2005).

En nuestro estudio a la pregunta ¿Conoces el manual de convivencia de tu escuela? (Gráfica 7), los encuestados respondieron de la siguiente manera: el 65,8\% dijo conocerlo, contra un importante $34,2 \%$, que manifestó no conocerlo, lo que plantea la necesidad en las escuelas objeto de estudio de hacer conocer esta herramienta que, bien diseñada, puede convertirse en una poderosa estrategia para la construcción de la sana convivencia en estos espacios.

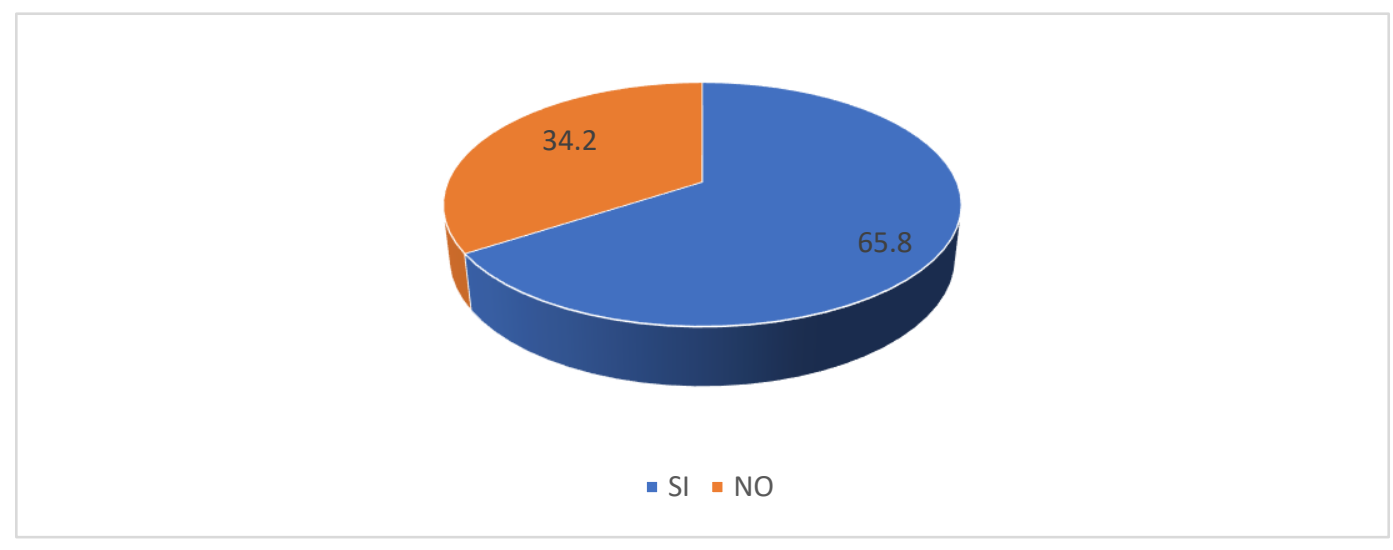

Gráfica $7^{\circ}$ ¿ ¿Conoce el manual de convivencia de su escuela?

Acerca de lo anterior, la Corte Constitucional, en su Sentencia. T-688 de 2005, expresa que los manuales de convivencia son la manifestación de los valores, ideales e intereses de los miembros de las comunidades educativas. Sobre la naturaleza del manual de convivencia, ha dicho la Corte Constitucional en la sentencia T- 859 de 2002 que éste

[...] tiene una naturaleza tripartita, pues de un lado reviste las características propias de un contrato de adhesión por el otro, constituye las reglas mínimas de convivencia escolar, dentro del ámbito de la autonomía conferida a los centros educativos y, finalmente, es también expresión de la participación y el pluralismo, toda vez que en su diseño concurre toda la comunidad educativa (directivos, padres de familia, docentes, egresados, alumnos). 
Si bien la sentencia arriba señalada, manifiesta que esta herramienta escolar debe ser el resultado de la consulta de los estamentos más importantes de la comunidad educativa, en la práctica los reglamentos escolares en su elaboración no cuentan con la participación activa de profesores, padres de familia, egresados y estudiantes. Al respecto, afirma Martínez Rojas: "en la construcción del Manual de Convivencia es importante tener en cuenta que este debe ser producto de un proceso de participación, buscando que todos se involucren y se sientan responsables de lo acordado como norma para la institución” (2014, p. 170).

Por otro lado, Pabón Mantilla y Aguirre Román (2007, p. 41), refiriéndose a la legitimidad de los manuales de convivencia, exponen: “[...] ahora bien, en la medida en que los manuales de convivencia representan los valores, ideales e intereses de toda la comunidad educativa, es evidente que en su elaboración deben participar activamente directivos, profesores, padres de familia, egresados y estudiantes”, y citando la sentencia T- 694 de 2002, de la Corte Constitucional, concluyen: "[...] este aspecto es de una relevancia tal, que incluso la Corte ha afirmado que la legitimidad del manual de convivencia depende de él”.

Martínez Rojas (2014) define el manual de convivencia como "un documento que hace parte del Proyecto Educativo Institucional de cada institución educativa y contiene el conjunto de principios, normas, procedimientos, acuerdos y demás aspectos que regulan y hacen posible la convivencia de sus miembros" (p.151).

\section{Contenido de los manuales de convivencia}

Es importante resaltar que la Carta Política le otorgó a la educación una esencial importancia, por la cual es considerada como derecho fundamental, derecho prestacional y un derecho-deber, en concordancia con el Art. 67 superior. Su naturaleza de derecho-deber implica que el estudiante no solo tiene un conjunto de derechos que le deben ser garantizados y respetados, es decir, que puede hacer exigibles, sino que también debe cumplir con determinadas obligaciones, en especial académicas y disciplinarias, contempladas en los reglamentos de las instituciones educativas. Así mismo, el artículo 42 numeral $4^{\circ}$ de la ley 1098 de 2006 o Código de la Infancia y la Adolescencia, referente a las obligaciones especiales de las instituciones educativas, establece que "para cumplir con su misión las 
instituciones educativas tendrán entre otras, la obligación de facilitar la participación de los estudiantes en la gestión académica del centro educativo".

El contenido mínimo previsto legalmente (ley 115 de 1994) para los Manuales de Convivencia de las instituciones educativas hace referencia a dos aspectos: normas de conducta de los alumnos (derechos, pautas de presentación personal, deberes y obligaciones) y de los profesores, las cuales buscan garantizar el mutuo respeto y establecimiento de límites en el ejercicio de los derechos fundamentales de los educandos y de la comunidad educativa, para hacer efectivo el fin supremo de la calidad, de la mejor formación moral, intelectual y física de los educandos. Por otra parte, el decreto 1860 de agosto 3 de 1994, en su artículo 17, con relación al contenido del manual de convivencia dispone que [...] el reglamento o manual de convivencia debe contener una definición de los derechos y deberes de los alumnos y de sus relaciones con los demás estamentos de la comunidad educativa.

En particular debe contemplar los siguientes aspectos:

1. Reglas de higiene personal y de salud pública que preserven el bienestar de la comunidad educativa, la conservación individual de la salud y la prevención frente al consumo de sustancias psicotrópicas.

2. Criterios de respeto, valoración y compromiso frente a la utilización y conservación de los bienes personales y de uso colectivo, tales como equipos, instalaciones e implementos.

3. Pautas de comportamiento en relación con el cuidado del medio ambiente escolar.

4. Normas de conducta de alumnos y profesores que garanticen el mutuo respeto. Debe incluir la definición de claros procedimientos para formular las quejas o reclamos al respecto.

5. Procedimientos para resolver con oportunidad y justicia los conflictos individuales o colectivos que se presenten entre miembros de la comunidad. Deben incluir instancias de diálogo y de conciliación.

6. Pautas de presentación personal que preserven a los alumnos de la discriminación por razones de apariencia.

7. Definición de sanciones disciplinarias aplicables a los alumnos, incluyendo el derecho a la defensa.

8. Reglas para la elección de representantes al Consejo Directivo y para la escogencia de voceros en los demás consejos previstos en el presente decreto. Debe incluir el proceso de elección del personero de los estudiantes.

9. Calidades y condiciones de los servicios de alimentación, transporte, recreación dirigida y demás conexos con el servicio de educación que ofrezca la institución a los alumnos.

10. Funcionamiento y operación de los medios de comunicación interna del establecimiento, tales como periódicos, revistas o emisiones radiales que sirvan de instrumentos efectivos al libre pensamiento y a la libre expresión.

11. En cargos hechos al establecimiento para aprovisionar a los alumnos de material didáctico de uso general, libros, uniformes, seguros de vida y de salud.

12. Reglas para uso del bibliobanco y la biblioteca escolar.

En este punto cabe la siguiente pregunta: ¿Y cuál es el límite en el contenido del manual de convivencia? 


\section{$\mathrm{Al}$ respecto, ha dicho la Corte Constitucional}

[...] los manuales de convivencia encuentran como límite último el respeto no solo de los derechos fundamentales y de la Constitución en general, sino también de la concreción legal que de ellos se haga. Su eficacia depende, en consecuencia, del grado de armonía con los derechos fundamentales y las disposiciones de rango superior, como ya ha tenido ocasión de reseñarlo la jurisprudencia de esta Corporación (Sentencia T-859 de 2002)

Es decir, que la ley y la Constitución deben constituirse en los faros orientadores de toda la normatividad contenida en los manuales de convivencia. Su contenido encuentra como límite último el respeto no solo de los derechos fundamentales y de las disposiciones constitucionales en general, sino también la acumulación legal que de ellos se haga. Su eficacia depende, en consecuencia, del grado de armonía con los derechos fundamentales y las disposiciones de rango superior. Al respecto, el Alto Tribunal Constitucional ha dicho:

[...] esta Corporación ha sostenido en reiteradas ocasiones, que las normas establecidas en los Manuales de Convivencia no pueden desconocer los principios y mandatos constitucionales, ya que la Constitución Política impera frente a todas y cada una de las relaciones que se establecen dentro del ordenamiento. No es dable, por tanto, que a través de la aplicación de normas establecidas en el manual de convivencia, se vean afectados o vulnerados derechos fundamentales de los participantes de la comunidad educativa (Corte Constitucional. Sentencia T-688 de 2005).

Igualmente, sostuvo en la misma sentencia:

[...] Obviamente, el texto del Manual de Convivencia no puede establecer reglas ni compromisos contrarios a la Constitución Política, ni imponer al alumno obligaciones desproporcionadas o contrarias a la razón, ni a la dignidad esencial de la persona humana.

De lo anterior, se puede deducir que las disposiciones consagradas en un Manual de Convivencia deben estar en armonía con lo dispuesto en la Constitución, respetando siempre los derechos fundamentales de los integrantes de la comunidad educativa. En caso de un manual de convivencia que vulnere derechos fundamentales, "se hará prevalecer los mandatos y preceptos superiores, inaplicando para el caso la cláusula correspondiente, en ese sentido" (Corte Constitucional. Sentencia T-688 de 2005)

No obstante, el Alto Tribunal en lo Constitucional también ha manifestado: 
[...] es posible que a través de instrumentos como el Manual de Convivencia se establezcan ciertas limitaciones al ámbito de autonomía personal de los estudiantes, con el fin de armonizar el desarrollo de las libertades de los educandos y el normal funcionamiento de una Institución Educativa, así como también, permitir el ejercicio pacifico de las libertades individuales y desarrollar la labor formadora y educativa que los colegios están llamados a cumplir; sin embargo, cuando ello ocurra, dicha limitación debe responder a criterios de razonabilidad, bajo el entendido de que no es posible afectar el núcleo esencial del derecho. La regulación además de ser razonable, también debe ser adecuada a los fines legítimos que persigue y proporcionada a los hechos que le sirven de fundamento (Corte Constitucional. Sentencia T-688 de 2005).

También ha dicho la Corte Constitucional:

En consecuencia, se reitera la doctrina sobre los alcances y límites de los manuales de convivencia concluyendo que en todos aquellos eventos en los cuales exista un conflicto entre los intereses estudiantiles y los intereses de la institución educativa respecto del tratamiento de una situación de convivencia o académica, es menester tener en cuenta las obligaciones, derechos y procedimientos que se fijan en el manual de convivencia del plantel, como carta de navegación que rige las relaciones dentro de un centro educativo, siempre y cuando éste se ajuste a los principios, derechos y deberes consagrados en la Constitución y responda al resultado del concurso efectivo de las diferentes voluntades que conforman la comunidad académica. Todo manual de convivencia debidamente debatido y analizado por la comunidad educativa, que respete los derechos, principios y deberes consagrados en la Constitución, será entonces legítimo y en consecuencia, al ser fruto del acuerdo de los diferentes miembros que conforman dicha comunidad y acogerse a la Constitución será acogido a plenitud por la comunidad educativa (Sentencia T-694 de 2002)

Es importante resaltar la ley 1620 de 2013, ya mencionada, indica que, con esta ley, se busca contribuir a la formación de ciudadanos activos que aporten a la construcción de una sociedad democrática, participativa, pluralista e intercultural, en concordancia con el mandato constitucional y la Ley General de Educación -Ley 115 de 1994.

En esta ley se definen, de manera muy precisa, algunos conceptos que sirven y servirán para la construcción y entendimiento de los manuales de convivencia, al dejar claro los conceptos relacionados con el maltrato que se da en las aulas de clases de nuestras instituciones a nivel nacional. En su artículo 2do, la ley define los siguientes términos:

Competencias ciudadanas: Es una de las competencias básicas que se define como el conjunto de conocimientos y de habilidades cognitivas, emocionales y comunicativas 
que, articulados entre sí, hacen posible que el ciudadano actúe de manera constructiva en una sociedad democrática.

\section{Educación para el ejercicio de los derechos humanos, sexuales y} reproductivos: es aquella orientada a formar personas capaces de reconocerse como sujetos activos titulares de derechos humanos, sexuales y reproductivos con la cual desarrollarán competencias para relacionarse consigo mismo y con los demás, con criterios de respeto por sí mismo, por el otro y por el entorno, con el fin de poder alcanzar un estado de bienestar físico, mental y social que les posibilite tomar decisiones asertivas, informadas y autónomas para ejercer una sexualidad libre, satisfactoria, responsable y sana en torno a la construcción de su proyecto de vida y a la transformación de las dinámicas sociales, hacia el establecimiento de relaciones más justas, democráticas y responsables.

Acoso escolar o bullying: Conducta negativa, intencional metódica y sistemática de agresión, intimidación, humillación, ridiculización, difamación, coacción, aislamiento deliberado, amenaza o incitación a la violencia o cualquier forma de maltrato psicológico, verbal, físico o por medios electrónicos contra un niño, niña, o adolescente, por parte de un estudiante o varios de sus pares con quienes mantiene una relación de poder asimétrica, que se presenta de forma reiterada o a lo largo de un tiempo determinado.También puede ocurrir por parte de docentes contra estudiantes, o por parte de estudiantes contra docentes, ante la indiferencia o complicidad de su entorno. El acoso escolar tiene consecuencias sobre la salud, el bienestar emocional y el rendimiento escolar de los estudiantes y sobre el ambiente de aprendizaje y el clima escolar del establecimiento educativo.

Ciberbullying o ciberacoso escolar: forma de intimidación con uso deliberado de tecnologías de información (internet, redes sociales virtuales, telefonía móvil y videojuegos online) para ejercer maltrato psicológico y continuado.

En todo caso, lo que sí debe quedar claro es el hecho de que las instituciones educativas deben garantizar en sus espacios y en el tiempo en que los estudiantes se encuentran a su 
cuidado la protección integral de los y las estudiantes y en sus reglamentos o manuales de convivencia este aspecto debe ser tenido en cuenta.

\section{La protección integral del niño, niña y adolescente en los espacios educativos}

En el consenso de la mayoría de las constituciones del mundo, y, en general, en el ámbito jurídico internacional, los derechos de los niños tienen una especial y marcada importancia. Es una propensión interestatal la búsqueda del bienestar de los niños y niñas para que tengan un crecimiento sano con todas las oportunidades brindadas por el Estado, la sociedad y la familia. La Constitución colombiana, por ejemplo, hace énfasis en que los derechos de los niños prevalecen sobre los de los demás y es un hecho de que debe ser así. Efectivamente, el artículo 44 superior establece:

Son derechos fundamentales de los niños: la vida, la integridad física, la salud y la seguridad social, la alimentación equilibrada, su nombre y nacionalidad, tener una familia y no ser separados de ella, el cuidado y amor, la educación y la cultura, la recreación y la libre expresión de su opinión. Serán protegidos contra toda forma de abandono, violencia física o moral, secuestro, venta, abuso sexual, explotación laboral o económica y trabajos riesgosos. Gozarán también de los demás derechos consagrados en la Constitución, en las leyes y en los tratados internacionales ratificados por Colombia. La familia, la sociedad y el Estado tienen la obligación de asistir y proteger al niño para garantizar su desarrollo armónico e integral y el ejercicio pleno de sus derechos. Cualquier persona puede exigir de la autoridad competente su cumplimiento y la sanción de los infractores. Los derechos de los niños prevalecen sobre los derechos de los demás.

Se entiende por protección integral de los niños, niñas y adolescentes, el reconocimiento como sujetos de derechos, la garantía y cumplimiento de los mismos, la prevención de su amenaza o vulneración y la seguridad de su restablecimiento inmediato en desarrollo del principio del interés superior. La protección integral se materializa en el conjunto de políticas, planes, programas y acciones que se ejecuten en los ámbitos nacional, departamental, distrital y municipal, con la correspondiente asignación de recursos financieros, físicos y humanos (Artículo $7^{\circ}$ de la ley 1089 de 2006).

La protección integral es un concepto a tener en cuenta en los espacios educativos. En la Sentencia C-273 de 2003, la Corte Constitucional aclaró la situación jurídica de la protección integral de la niñez, mucho antes de la entrada en vigencia del Código de Infancia y 
Adolescencia. De esta manera se daba un auxilio jurisprudencial a la normatividad ya existente. Al respecto, señaló la Corte:

[...] la protección integral de los derechos del niño se hace efectiva a través del principio del interés superior del niño, consagrado en el mismo artículo 44 Superior al disponer que "los derechos de los niños prevalecen sobre los derechos de los demás", y en el numeral $1^{\circ}$ del artículo tercero de la Convención de los Derechos del Niño, en virtud del cual "En todas las medidas concernientes a los niños que tomen las instituciones públicas o privadas de bienestar social, los tribunales, las autoridades administrativas o los órganos legislativos, una consideración primordial a que se atenderá será el interés superior del niño”.

Se ha de anotar también que existen instrumentos legales internacionales, que contienen la exigencia de la protección integral de los niños y orientan su materialización. El más importante, es quizás, la Convención Internacional de los Derechos del Niño, que reúne en su contenido los derechos civiles, políticos, sociales, económicos y culturales relacionados con estos, en un tratado vinculante. Fue adoptado por la Asamblea de la Naciones Unidas el 20 de noviembre de 1989, y ratificado por Colombia mediante la Ley 12 de 1991. La Convención constituye el marco fundamental a partir del cual los gobiernos desarrollan sus políticas para la niñez y la adolescencia.

El artículo 44 de la Constitución Política colombiana, junto con la Convención mencionada anteriormente, constituyen el marco de los derechos de los niños como importantes en los fines del Estado. Por su parte, la Ley 1098 del año 2006 o Código de Infancia y adolescencia, es la que reglamenta la política de protección integral de los niños, niñas, y adolescentes en Colombia, desarrollando los principios superiores estatuidos en las normas ut supra. Este código tiene por finalidad garantizar a los niños, a las niñas y a los adolescentes su pleno y armonioso desarrollo para que crezcan en el seno de la familia y de la comunidad, en un ambiente de felicidad, amor y comprensión. Prevalecerá el reconocimiento a la igualdad y la dignidad humana, sin discriminación alguna. Tiene por objeto establecer normas sustantivas y procesales para la protección integral de los niños, las niñas y los adolescentes, garantizar el ejercicio de sus derechos y libertades consagrados en los instrumentos internacionales de Derechos Humanos, en la Constitución Política y en las leyes, así como su restablecimiento. Dicha garantía y protección será obligación de la familia, la sociedad y el Estado (Artículos $1^{\circ}$, y $2^{\circ}$ de la ley 1098 del 2006). 
Se tiene entonces que la escuela es una institución llamada a formar dentro de una cultura democrática, en los que los principios de ciudadanía deben ser puestos en práctica ampliamente en el contexto educativo. En ese sentido, el artículo 19 de la Convención Internacional de los Derechos del Niño, dispone:

[...] los Estados Partes adoptarán las medidas legislativas, administrativas, sociales y educativas apropiadas para proteger al niño contra toda forma de violencia, perjuicio o abuso físico o mental, descuido o trato negligente, malos tratos o explotación, incluido el abuso sexual, mientras el niño se encuentre bajo la custodia de los padres, de un tutor o de cualquier otra persona que lo tenga a su cargo.

En Colombia. la ley General de la Educación 115 de febrero 8 de 1994, en el artículo 5º, señala los fines de la educación y, particularmente en el inciso $2^{\circ}$ de dicho artículo, plantea que uno de esos fines es "la formación en el respeto a la vida y a los demás derechos humanos, a la paz, a los principios democráticos, de convivencia, pluralismo, justicia, solidaridad y equidad, así como el ejercicio de la tolerancia y de la libertad".

De esta manera, se evidencian las responsabilidades necesarias que desde los centros educativos deben ser tenidas en cuenta para formar ciudadanos desde la primera edad escolar. La ley 1098 de 2006 o Código de infancia y adolescencia, dispone en el artículo 43, referido a la obligación ética fundamental de los establecimientos educativos, que "las instituciones de educación primaria y secundaria, públicas y privadas, tendrán la obligación fundamental de garantizar a los niños, niñas y adolescentes el pleno respeto a su dignidad, vida, integridad física y moral dentro de la convivencia escolar”, y, para tal efecto, señala el artículo en el numeral 2 y 3 que deberán:

"2. Proteger eficazmente a los niños, niñas y adolescentes contra toda forma de maltrato, agresión física o psicológica, humillación, discriminación o burla por parte de los demás compañeros y de los profesores".

"3. Establecer en sus reglamentos los mecanismos adecuados de carácter disuasivo, correctivo y reeducativo para impedir la agresión física o psicológica, los comportamientos de burla, desprecio y humillación hacia niños, niñas y adolescentes con dificultades en el aprendizaje, en el lenguaje o hacia aquellos con capacidades sobresalientes o especiales".

En el estudio realizado por Mújica y Mazuera (2006), se afirma que son varias las intenciones pedagógicas que se propone con la existencia de estos manuales: 
- Contribuir a la formación de la personalidad y capacidad de asumir con responsabilidad derechos y deberes.

- Proporcionar una sólida formación ética moral y fomentar la práctica del respeto por los Derechos Humanos.

- Propiciar en la institución educativa prácticas democráticas para el aprendizaje de principios y valores.

- Estimular la autonomía y la responsabilidad.

- Crear y fomentar una conciencia de solidaridad.

- Lograr la armonía, la comprensión y la participación entre los miembros de la comunidad educativa.

- Regular las acciones que se realizan en la institución educativa.

Ha indicado el Ministerio de Educación, en la página del sitio de colombiaaprende.com, que, aunque cada colegio define el perfil y estilo de su manual de convivencia, en las reflexiones, discusiones y contenidos es relevante incorporar los aspectos que se mencionan a continuación:

Participación y procesos de construcción de democracia: Además de dar cuerpo a las instancias de participación y definir los procesos de elección de representantes a los cuerpos colegiados, es preciso asegurar que el manual opere como un regulador interno que promueva un ejercicio integral de la democracia ${ }^{2}$.

Respeto y bienestar integral: Orientar los contenidos para lograr el fortalecimiento del bienestar de la comunidad educativa a partir de la definición de las bases del respeto común, lo que también incluye el respeto por los bienes personales y de uso colectivo, la utilización y conservación de equipos, instalaciones e implementos.

Espacios de diálogo y conciliación: Establecer las pautas para la resolución de los conflictos individuales o colectivos, las instancias de diálogo y conciliación entre los integrantes de la comunidad educativa, y los procedimientos para la formulación de quejas o reclamos.

Vida sana y prevención en salud: Asegurar la definición de principios y mecanismos para la promoción de un ambiente propicio para desarrollar individual y colectivamente

\footnotetext{
2 Al respecto, existen muchas propuestas alrededor de mejorar esta participación y procesos de construcción en democracia en la escuela. Uno de ellas tiene que ver en la construcción en valores durante el año escolar, según lo plantea el texto "Los valores y su incidencia en el lenguaje: una propuesta para la paz desde la educación preescolar", de Margarita Rosa de la Hoz Pertuz, para quien es deseable "recrear una atmósfera de seguridad, solidaridad, respeto, tolerancia", mediatizado por la educación en valores", teniendo en cuenta "tanto la acción del conjunto y la subjetividad en la constitución del objeto como la particular perspectiva de este, derivada de la ubicación en un entorno ecológico, histórico y social desde donde se construye ese saber". Esta propuesta curricular fundamentada en Ética y Valores Humanos desarrollada los cuatro pilares fundamentales de la educación, basados en aprender a conocer, aprender a hacer, aprender a ser y aprender a convivir, demostrándose que "el valor de mayor relevancia para los niños es el de la paz y la justicia" (pp.200-208)".
} 
hábitos de vida saludable. Esto implica tener en cuenta circunstancias y contextos relacionados con el consumo de alcohol y de sustancias psicotrópicas y prevención de enfermedades de transmisión sexual, entre otros. En relación con los servicios de alimentación, transporte y recreación ofrecidos por la institución, es preciso acordar sus estándares de calidad y los mecanismos para asegurarlos.

Comunicación: Estructurar los espacios de interlocución entre la comunidad educativa, así como la organización, funcionamiento y operación de los medios de comunicación internos con el fin de que sean instrumentos efectivos para el ejercicio del libre pensamiento y la libre expresión.

Medio ambiente sostenible: Incorporar principios y compromisos relacionados con la responsabilidad en el manejo de los recursos naturales y el establecimiento de comportamientos adecuados alrededor de la conservación de la naturaleza. Esto tiene que ver, entre otros asuntos, con la definición de procesos regulados en la disposición y manejo de residuos, reciclaje, ahorro de agua y de energía, reforestación, etc.

Administración y gestión: Consignar los principios y normas relativos a los cobros periódicos de los servicios académicos.

Higiene: Especificar las normas de higiene personal e institucional que cobijan a todos los actores, con lo que se debe asegurar la pulcritud de los miembros del plantel, así como de las instalaciones educativas, los servicios prestados por el colegio y aquellos que se contraten con particulares.

\section{Sanciones en los manuales de convivencia}

Según la Ley general de Educación, el rector del establecimiento educativo tiene facultad para sancionar y otorgar distinciones, y podrá otorgar distinciones o imponer sanciones a los estudiantes según el reglamento o manual de convivencia de éste, en concordancia con lo que al respecto disponga el Ministerio de Educación Nacional. Las sanciones y procedimientos que se apliquen, en virtud del incumplimiento de las normas contenidas en los manuales de convivencia, en las instituciones educativas, deben respetar todos los principios y garantías constitucionales del debido proceso, sin distinguir si se trata de un plantel educativo público o privado. 
Esto implica que la imposición de una sanción disciplinaria, por parte de las instituciones educativas, debe estar precedida siempre del agotamiento de un procedimiento previamente definido, en el cual el implicado haya podido participar, presentar su defensa y controvertir las pruebas presentadas en su contra (Sentencia T-722 de 2000 y T-437 de 2005). El Código de la Infancia y la Adolescencia en su artículo 45 prohíbe las sanciones crueles, humillantes o degradantes estableciendo que "los directores y educadores de los centros públicos o privados de educación formal, no formal e informal, no podrán imponer sanciones que conlleven maltrato físico o psicológico de los estudiantes a su cargo, o adoptar medidas que de alguna manera afecten su dignidad. Así mismo, queda prohibida su inclusión bajo cualquier modalidad, en los manuales de convivencia escolar".

Además, los centros educativos, para definir una sanción en sus manuales de convivencia, deberán tener en cuenta los criterios para la definición de la misma, establecidos en el artículo 179 del Código de la Infancia y la Adolescencia, las cuales son:

1. La naturaleza y gravedad de los hechos

2. La proporcionalidad e idoneidad de la sanción atendidas las circunstancias y gravedad de los hechos; las circunstancias y necesidades del adolescente y las necesidades de la sociedad.

3. La edad del adolescente.

4. La aceptación de cargos por el adolescente.

5. El incumplimiento de los compromisos adquiridos con el juez.

6. El incumplimiento de las sanciones.

\section{A manera de conclusión}

- Un fenómeno azota con bastante regularidad la comunidad educativa internacional en el nuevo milenio. Se trata del bullying o matoneo, una modalidad de acoso impropio hacia estudiantes discriminados, ya sea por su religión, raza, condición social, y/o académica, que ha empezado a inquietar sobremanera las instituciones encargadas de regular los ámbitos de la educación. No en vano, cabe decir. El matoneo ha causado muchas consecuencias críticas, e incluso llevando al suicidio de estudiantes, o su intento. Se ha convertido en una actuación peligrosa, por parte de estudiantes, y muchas veces de los profesores. De esta manera la vida de la institución educativa se ve alterada por las manifestaciones de violencia y victimización escolar donde su gran mayoría los niños, niñas y adolescentes son los protagonistas. 
- Esto ha llamado la atención a los investigadores, comunidad educativa en general, que deberían temer como objetivos, buscar explicaciones al fenómeno y corregir dichas manifestaciones, pero se encuentra que en los pocos o nulos estudios sobre el tema, no existen respuestas a los interrogantes dada la escasez de investigaciones existentes, por lo menos en lo que al Distrito de Barranquilla se refiere. En el otro lado de la balanza, por el contrario, hay bastante más estudios sobre violencia de género, en la que la mujer es vista desde el punto de calidad de víctima y no como una posible gestora de conductas violentas.

- La Convención sobre los Derechos del Niño exige a los Estados partes que tomen las medidas apropiadas para garantizar que en las escuelas la disciplina se administre de modo acorde con este instrumento normativo internacional. Se trata, por tanto, de ver la escuela como una institución educativa que tiene la co-responsabilidad ética, política y moral de constituirse en escenario de formación y socialización en el que, como tal, circulan múltiples sentidos, se producen variados aprendizajes, se abre la opción a la negociación de la diferencia y se funda la convivencia como una expresión de la autonomía, la libertad y la dignidad humana. (Echavarría Grajales: 2003, p.3)

- Es insoslayable que existe el escenario jurídico suficiente y pertinente para poner en marcha una política más eficiente con respecto a la situación de los niños en Colombia, cumpliendo así con el cometido constitucional e internacional de la protección integral de la niñez. Es posible, teniendo en cuenta los instrumentos internacionales de protección de los niños, una política internacional y regional con el fin de lograr el mismo fin. Hace falta, única y exclusivamente, la voluntad estatal y la colaboración social.

- En las escuelas es necesario un manual de convivencia escolar porque es una guía que se anticipa a las situaciones conflictivas que puedan dañar las relaciones armoniosas entre la comunidad educativa. Constituye una estrategia que se propone como elemento mediador de las situaciones conflictivas que surgen en la escuela entre los distintos actores de la misma. 


\section{Referencias}

Almenares-Aleaga, M.; Louro Bernal, I. \& Ortiz Gómez, M. (1999). Comportamiento de la violencia intrafamiliar. Revista Cubana Medicina General Integral V. 15 N`3 285- 92. Ciudad de La Habana mayo-junio 1999. Editorial Ciencias Médicas.

Agenda Pandi. Friends United Foundation (2015). La intimidación escolar no es un juego de niños... Estado, familias y colegios responsables de prevenir cualquier caso de bullying. Disponible en:

http://www.agenciapandi.org/wpcontent/uploads/2015/Reportajes/Intimidacion_escol ar.pdfConsultado el 18 de agosto de 2016

Bembibre, A. (2013) Convivencia. Disponible en: importancia.org. Fecha: 21/07/2013. URL: https://www.importancia.org/convivencia.php. Consultado: 18 de agosto de 2016

Calmaestra, J. et al (2016). Yo a eso no juego. Bullying y cyberbullying en la infancia. Save The Children España. Disponible en: https://www.savethechildren.es/sites/default/files/imce/docs/yo_a_eso_no_juego.pdf. Consultado: diciembre de 2016

Castro, A (2006). Violencia silenciosa en la escuela. Dinámica del acoso escolar y laboral. Buenos Aires-Argentina- Editorial Bonum

Cortés, D (2016). ¿Qué es la convivencia escolar? Disponible en http://aprende.colombiaaprende.edu.co/es/node/91787. Consultado: 15 de noviembre de 2016

Chaux-Torres, E., \& Velásquez Niño, A. M. (2008). Violencia en los colegios de Bogotá: contraste internacional y algunas recomendaciones. Revista Colombiana de Educación, (55). https://doi.org/10.17227/01203916.7569.

De La Hoz-Pertuz, M. (2018). Los valores y su incidencia en el lenguaje: una propuesta para la paz desde la educación preescolar. En Revista Cedotic 3 (1). 192-212. Disponible en:

http://investigaciones.uniatlantico.edu.co/revistas/index.php/CEDOTIC/article/view/2 037

Echavarría-Grajales, C (2003). La escuela: un escenario de formación y socialización para la construcción de identidad moral. En: Revista latinoamericana de ciencias sociales, niñez y juventud. 1 (2). julio/diciembre. 2003 Manizales.

Gómez, Nashiki. (2014). La violencia de alumnos hacia maestros en escuelas secundarias de Colima, México. En Pensamiento Educativo. Revista de Investigación Educacional Latinoamericana 2014, 51(2), 19-34. Disponible en 
https://www.bing.com/search?q=La+violencia+de+alumnos+hacia+maestros+en+esc uelas+secundarias+de+Colima $\% 2 \mathrm{C}+\mathrm{M} \% \mathrm{C} 3 \%$ A9xico\&form=EDNTHT\&mkt=esco\&httpsmsn=1\&refig=266e40ad41f94eb2bd5590e734a12314\&PC=LCTS\&sp=$1 \& \mathrm{pq}=\mathrm{la}+\mathrm{violencia}+\mathrm{de}+\mathrm{alumnos}+\mathrm{hacia}+$ maestros+en+escuelas+secundarias+de+coli $\mathrm{ma} \% 2 \mathrm{C}+\mathrm{m} \% \mathrm{C} 3 \% \mathrm{~A} 9 \mathrm{xico} \& \mathrm{sc}=0$ $80 \& q s=n \& s k=\& c v i d=266 e 40 \mathrm{ad} 41 \mathrm{f} 94 \mathrm{eb} 2 \mathrm{bd} 5590 \mathrm{e} 734 \mathrm{a} 12314$.

Consultado en diciembre de 2016

Hoyos, O. (2005). Caracterización del maltrato entre iguales en una muestra de colegios de Barranquilla, Colombia. Psicología desde el Caribe, 016, 1-28. Disponible en http://hdl.handle.net/10584/845._Consultado en diciembre de 2016

Le Blanc, M. (1999). L'évolution de la violence chez les adolescents québécois phénomène et prévention. Criminologie, vol. 32, n 1, 1999, p. 161-194. Université de Montréal. Canadá

Martínez-Rojas, J. (2014). El manual de convivencia y la prevención del bullyng. Bogotá: Editorial Magisterio

Ministerio de Educación. Sanciones del Manual de Convivencia. (2016) Consulta 2016-ER-027640. Disponible en: https://www.mineducacion.gov.co/1759/articles357092_archivo_pdf_Consulta.pdf

Aguilar-Ávila, A; Sánchez Plazas. M. C. (2007). Aprendiendo a vivir juntos en comunidad. Programa Formación de formadores para la organización comunal. Ministerio de Educación. Disponible en: http://colombiaaprende.edu.co/html/home/1592/article-239844.html. Consultado el 23 de noviembre de 2016

Organización Mundial de la Salud, Organización Panamericana de la Salud (2002). Informe mundial sobre la violencia y la salud: resumen. Washington, D.C. Oficina Regional para las Américas de la Organización Mundial de la Salud

Organización de Naciones Unidas (2006). Informe del experto independiente para el estudio de la violencia contra los niños, de las Naciones Unidas. Consultado en noviembre de 2016. Disponible en https://www.unicef.org/violencestudy/reports/SG_violencestudy_sp.pdf. Consultado en diciembre de 2016

Organización de Naciones Unidad. Convención de los Derechos de los niños en Colombia. Disponible en: http://www.unicef.com.co/derechos-de-ninas-y-ninos/la-convencion-delos-derechos-de-los-ninos-en-colombia/. Consultado en diciembre de 2016 
Pabón-Mantilla, A. y Aguirre Román, J. (2007). Justicia y derecho en la convivencia escolar. Bucaramanga. Universidad Industrial de Santander

Parra-Sandoval, R; González, A; Moritz, O; Blandón, A y Bustamante, R. (1992). La escuela violenta. Bogotá: Fundación FES-Tercer Mundo Editores.

Piñuel, I. (2006). Violencia contra profesores en la enseñanza pública de la comunidad de Madrid. Estudio Cisneros VIII. Disponible en: https://es.scribd.com/document/7129406/Informe-cisneros-VIII-Violencia-ContraLos-Profesores

Pereira, B., Neto, C., Smith, P. y Angulo, J.C. (2002). Reinventar los espacios de recreo para prevenir la violencia escolar. Cultura y Educación, 14(3), 297-311.

Pereira, B., Neto, C., Smith, P. y Angulo, J.C. (2002). Reinventing playgrounds to stop school bullying, Cultura y Educación, 14:3, 297-311. DOI: $10.1174 / 11356400260366115$

República de Colombia. Corte Constitucional. Sentencia T-688 de 2005

República de Colombia. Corte Constitucional. Sentencia T 478 de 2015

República de Colombia. Corte Constitucional Sentencia T-905 de 2011

República de Colombia. Corte Constitucional Sentencia T- 859 de 2002

República de Colombia. Corte Constitucional Sentencia T-688 de 2005

República de Colombia. Corte Constitucional Sentencia T- 694 de 2002

República de Colombia. Corte Constitucional Sentencia C-273 de 2003

República de Colombia. Corte Constitucional Sentencia T-722 de 2000

República de Colombia. Corte Constitucional Sentencia T-437 de 2005

República de Colombia. Ley 1620 de 2013.

República de Colombia. Ley 115 de 1994 o Ley General de Educación

República de Colombia. Decreto 1860 de agosto 3 de 1994

República de Colombia. Ley 1089 de 2006

República de Colombia. Constitución Política de 1991

República de Colombia. (2006) Ley de infancia y adolescencia № 1098 de 2006.

Unicef- Francia (2011). Une enquête de victimation et climat scolaire auprès d'élèves du cycle 3 des écoles élémentaires. Observatoire International de la Violence a l'Ecole. Disponible en:

https://www.unicef.fr/sites/default/files/userfiles/UNICEF_FRANCE_violences_scol aires_mars_2011.pdf. Consultado en junio de 2016. 
Valencia-Murcia, F. (2004) Conflicto y violencia escolar en Colombia: Lectura breve de algunos materiales escritos en Revista científica Guillermo de Ockham. Vol. 7 (1). Enero-Junio de 2004. Disponible en:

http://www.usbcali.edu.co/images/stories/archivos/investigaciones/PDF_revista/Vol_ 2N1/02_Conflicto_violencia_escolar.pdf._Consultado en junio de 2015.

Valencia-Murcia, F; Mazuera, V (2006). La figura del manual de convivencia en la vida escolar. Elementos para su comprensión. Revista Científica Guillermo de Ockham, vol. 4, núm. 1, enero-junio, pp. 119-131. 